\title{
Macroscopic Tribological Testing of Alkanethiol Self-assembled Monolayers (SAMs) Pin-on-disk Tribometry with Elastomeric Sliding Contacts
}

\author{
Journal Article \\ Author(s): \\ Lee, Seunghwan; Heeb, Raphael; Nagaiyanallur, Venkataraman V.; Spencer, Nicholas D. \\ Publication date: \\ 2007-12 \\ Permanent link: \\ https://doi.org/10.3929/ethz-b-000003315
}

Rights / license:

In Copyright - Non-Commercial Use Permitted

Originally published in:

Tribology Letters 28(3), https://doi.org/10.1007/s11249-007-9266-1 


\title{
Macroscopic Tribological Testing of Alkanethiol Self-assembled Monolayers (SAMs): Pin-on-disk Tribometry with Elastomeric Sliding Contacts
}

\author{
Seunghwan Lee - Raphael Heeb - Nagaiyanallur V. Venkataraman • \\ Nicholas D. Spencer
}

Received: 12 July 2007/ Accepted: 24 August 2007/Published online: 26 September 2007

(C) Springer Science+Business Media, LLC 2007

\begin{abstract}
We demonstrate that the frictional properties of alkanethiol self-assembled monolayers (SAMs) with various surface-chemical and structural features can be investigated on a macroscopic scale by employing an elastomer as the sliding partner in pin-on-disk tribometry. The mild contact conditions at the elastomeric tribological interface allow the SAM films to remain virtually intact despite the tribological stress. Sliding contact between SAMs and elastomers over the speed range available from an ordinary tribometer in a liquid environment induced a broad range of lubrication mechanisms, ranging from boundary to fluid-film lubrication regimes. Thus, the impact of both the chemical and structural characteristics of SAMs on the formation of fluid films and interfacial friction forces could be probed in the absence of wear processes. Given the large SAM "toolbox" that is readily available for the modification of surface-chemical characteristics, this approach provides an opportunity to investigate the influence of surface chemistry on the frictional properties of elastomeric tribological contacts.
\end{abstract}

Keywords Self-assembled monolayers (SAMs) . Elastomer · Pin-on-disk tribometry · Boundary lubrication . Soft elastohydrodynamic lubrication (soft EHL)

S. Lee $\cdot$ R. Heeb $\cdot$ N. V. Venkataraman $\cdot$ N. D. Spencer $(\bowtie)$ Laboratory for Surface Science and Technology, Department of Materials, ETH Zurich, Wolfgang-Pauli-Strasse 10, CH-8093 Zurich, Switzerland

e-mail: spencer@mat.ethz.ch

\section{Introduction}

In the past two decades, self-assembled monolayers (SAMs) generated from alkanethiols and alkylsilanes have been extensively studied as model systems for boundary lubricants [1-24]. Since the structure and chemistry of SAM films can be systematically tailored at the molecular level, the majority of reports have focused on the study of friction and lubricating properties of these systems under nanoscale contact conditions [1-18]. Technically, this has become possible for two reasons; firstly, SAMs can be readily generated on substrates displaying extremely smooth surfaces, such as monocrystalline gold, mica, and highly polished silicon, and thus boundary lubricant films with ideally smooth morphology have become available. As a comparison, it is worth noting that more classical boundary lubricant films, such as fatty acids and alcohols [25-28], have generally been formed on polished metal/ metal oxide surfaces, which display much higher surface roughness. Secondly, as the counterface to these boundary lubricant films, a slider consisting of a single asperity, such as the atomic force microscope (AFM) tip [29, 30], has become available. Thus, the control of contact pressure within the contact area became feasible by simply controlling the external load. This is important in that tribological stress could be applied exclusively onto the SAM films, i.e., without penetrating to the underlying substrate, and thus their tribological properties as boundary-lubricant films can be probed. In contrast, tribological contacts involving SAM films probed by more conventional, macroscale approaches, such as pin-on-disk tribometry [19-24], have generally resulted in irreversible damage to the samples, both the SAM films and the supporting substrates, which renders the interpretation of the observed tribological properties far more complicated. 
Clearly, this is due to the multi-asperity contacts arising from the counterpart roughness, e.g., the macroscale slider (pin), and the resulting uncontrolled, extremely high local contact pressures.

The poor mechanical durability of SAM films, and often of the supporting substrates themselves in addition, is a major barrier to fundamental tribological studies of SAM films on a macroscopic scale. This problem, however, can be readily overcome if a highly compliant material, such as a rubber, is employed as the sliding counterpart to the SAM films. Under ordinary tribometer experiment conditions, the apparent contact pressure applied by an elastomer can be easily maintained below the MPa range, and due to its high compliance, the surface asperities of the elastomer can readily flatten out under pressure. Thus, the wear problems arising from uncontrolled asperity contact can be avoided. In fact, this configuration, either 'soft' slider on 'rigid' track or 'rigid' slider on 'soft' track, has routinely been employed in tribological studies of elastomers [31-33], especially in soft elastohydrodynamic lubrication (soft EHL) studies [34-43]. As schematically depicted in Fig. 1,

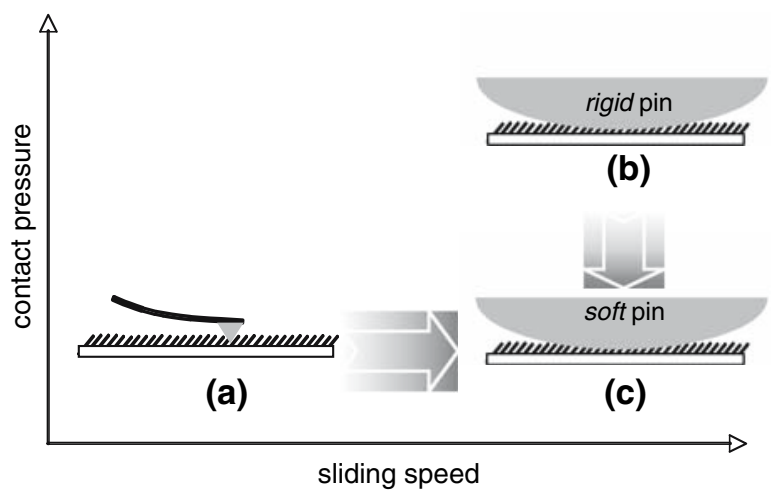

(a)

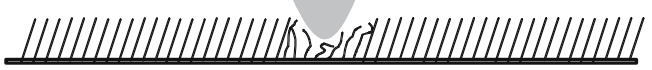

(b)

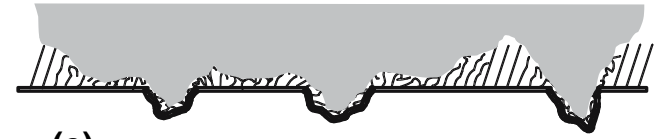

(c)

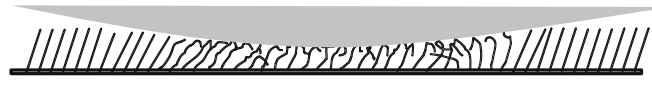

Fig. 1 A pressure-versus-sliding-speed diagram showing the contact configuration of an elastomeric slider on self-assembled monolayer (SAM) films: schematic illustrations for (a) single-asperity contacts on a nanoscopic scale as in AFM (low contact pressure, low speed), (b) multi-asperity contacts on a macroscopic scale as in conventional pin-on-disk tribometry employing rigid sliders (high contact pressure, high speed) and (c) soft contacts on a macroscopic scale by employing an elastomeric slider in pin-on-disk tribometry (low contact pressure, high speed) the effect of using an elastomeric slider for pin-on-disk tribometric studies of SAM films is to reduce the contact pressure to a level typically available from nanotribological contacts or lower, while the contact area and sliding speed are maintained at levels typical for macrotribological studies. Thus, the tribological properties of SAM films can be investigated in a wear-less regime, as is the case with nanotribological approaches, yet with the possibility of both macroscopic contact area and high sliding speeds. Furthermore, the contact area is large enough that standard surface-analytical approaches can readily access it to characterize the structural and chemical changes present after tribological stress; currently, no generally available surface-analytical approach can access the contact area generated by an AFM probe other than AFM itself.

We consider that this approach-soft slider on SAM films/rigid substrate-is particularly useful to investigate the role of surface chemistry on the efficacy of lubricantfilm formation, which is crucial in the soft elastohydrodynamic lubrication (soft EHL) regime. Our recent studies, [34, 35] involving water and poly(dimethylsiloxane) (PDMS) as lubricant and elastomeric tribopair, respectively, have shown that the formation of a soft EHL film is determined not merely by the bulk mechanical and rheological properties of the tribosystem alone as predicted by classical theory [44, 45], but that the surface-chemical properties of tribopairs also play a significant role; when the surface of the tribopair is insufficiently wetted by the lubricant, the predicted formation of an EHL film is significantly retarded, even if the bulk mechanical properties meet the conditions for the formation of a soft-EHL film. Given the wealth of useful approaches that have been established in self-assembly techniques to modify surfacechemical characteristics, the effects of a broad range of surface-chemical modifications on soft EHL can be conveniently explored. In the present article, we aim to establish this methodology by employing SAM systems whose tribological properties have been well established, allowing us to focus on testing the proposed methodology.

\section{Materials and Methods}

\subsection{Self-assembled Monolayers (SAMs)}

Three types of SAM films have been prepared by spontaneous adsorption from ethanolic solutions of 11-mercaptoundecanol $\left(\mathrm{HS}\left(\mathrm{CH}_{2}\right)_{11} \mathrm{OH}\right)$, 1-dodecanethiol $\left(\mathrm{HS}\left(\mathrm{CH}_{2}\right)_{11} \mathrm{CH}_{3}\right)$, and 1-hexanethiol $\left(\mathrm{HS}\left(\mathrm{CH}_{2}\right)_{5} \mathrm{CH}_{3}\right)$ onto polycrystalline gold surfaces deposited on glass. For simplicity, these SAMs are abbreviated as $\mathbf{C}_{\mathbf{1 1}} \mathbf{O H}, \mathbf{C}_{\mathbf{1 1}} \mathbf{C H}_{\mathbf{3}}$, and $\mathbf{C}_{\mathbf{5}} \mathbf{C H}_{\mathbf{3}}$, respectively, throughout this article. A schematic illustration of the SAM films on gold substrates generated from these molecules is 
(a)

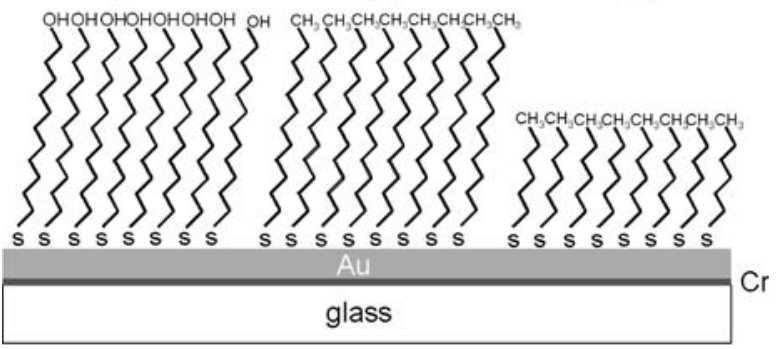

Fig. 2 Schematic representation of the alkanethiol SAM films on gold substrate used in this study: (a) 11-mercaptoundecanol $\left(\mathrm{HS}\left(\mathrm{CH}_{2}\right)_{11} \mathrm{OH}\right)$, (b) 1-dodecanethiol $\left(\mathrm{HS}\left(\mathrm{CH}_{2}\right)_{11} \mathrm{CH}_{3}\right)$ and (c) 1hexanethiol $\left(\mathrm{HS}\left(\mathrm{CH}_{2}\right)_{5} \mathrm{CH}_{3}\right)$

presented in Fig. 2. The alkanethiols (Sigma-Aldrich, Switzerland) were used as received. Ethanol (Fluka, Switzerland) was used as solvent for alkanethiol solutions $(1 \mathrm{mM})$. Soda-lime glass microscope slides (SuperFrost, Menzel-Gläser, Braunschweig, Germany) were cut into $\sim 2.5 \times 2.5 \mathrm{~cm}^{2}$ pieces and used as substrates for the gold films. The glass substrates were cleaned according to the following procedure; (a) ultrasonication in ethanol four times for $15 \mathrm{~min}$ - the solvent was exchanged each time (b) $\mathrm{O}_{2}$ plasma for 2 min (high power, Harrick Plasma Cleaner/Sterilizer, Ossining, NY, USA). After cleaning, the substrates were coated with a 10-nm adhesive layer of chromium, followed by 100 -nm layer of gold by thermal evaporation (MED020 coating system, BALTEC, Balzers, Lichtenstein). The SAM films were generated by immersion of the substrates in the relevant $1 \mathrm{mM}$ ethanolic alkanethiol solution overnight. Prior to the immersion step, the gold substrates were rinsed with pure ethanol and subsequently dried with nitrogen.

\subsection{Poly(dimethylsiloxane)(PDMS)}

Poly(dimethylsiloxane) (PDMS) was employed as an elastomeric counterpart (pin) against the SAM films/gold/ glass in pin-on-disk tribometry experiments. The PDMS pins were prepared from a commercial silicone elastomer kit (SYLGARD ${ }^{\circledR} 184$ silicone elastomer, base and curing agent, Dow Corning, Midland, MI, USA). In order to prepare PDMS pins with hemispherical ends, a commercial polystyrene cell-culture plate with round-shaped wells (radius $3 \mathrm{~mm}$, 96 MicroWell Plates $^{\mathrm{TM}}$, NUNCLON ${ }^{\mathrm{TM}}$ Delta Surface, Denmark) was employed as master. The PDMS pins were prepared according to a conventional recipe [34, 35]. Briefly, the base and crosslinker of the SYLGARD ${ }^{\circledR}$ 184 elastomer kit were mixed at 10:1 ratio (by weight). The foams generated during mixing were removed by gentle vacuum. The mixture was transferred into the master and incubated in an oven $\left(\sim 70{ }^{\circ} \mathrm{C}\right)$ overnight. Planar PDMS sheets were also prepared for the characterization of surface hydrophilicity according to the same procedure.

The surface of the PDMS pins was hydrophilized by means of air plasma treatment for $1 \mathrm{~min}$, and thus they are denoted as ' $o x$-PDMS' throughout this article. For a control experiment, the PDMS pins were immersed in $n$-hexane, to extract uncrosslinked monomer species prior to air-plasma treatment; the solvent, $n$-hexane, was exchanged twice during $24 \mathrm{~h}$.

\subsection{Water Contact Angle Measurements}

The surface hydrophilicity of the tribopairs, including the SAM films and $o x$-PDMS, was characterized by measuring static water contact angles, $\theta_{\mathrm{w}}$, by employing a contactangle goniometer (Ramé-Hart model 100). All contactangle measurements were averaged over five runs.

\subsection{Ellipsometry}

The dry thicknesses of the SAM films were determined by variable angle spectroscopic ellipsometry (VASE, M2000F, L.O.T. Oriel GmbH, Germany). Measurements were conducted under ambient conditions at three angles of incidence $\left(65^{\circ}, 70^{\circ}\right.$, and $\left.75^{\circ}\right)$ in the spectral range of 370 $995 \mathrm{~nm}$. Measurements were fitted with the WVASE32 analysis software using a three-layer model for an organic layer on a gold/glass substrate.

\subsection{Polarization-Modulation Infrared Reflection-Absorption Spectroscopy (PM-IRRAS)}

Polarization-modulation infrared reflection-absorption spectra (PM-IRRAS) were recorded on a Bruker IFS 66v IR spectrometer, equipped with a PMA37 polarizationmodulation accessory (Bruker Optics, Germany). The interferogram from the spectrometer's external beam port was passed through a KRS-5 wire-grid polarizer and a $\mathrm{ZnSe}$ photoelastic modulator before reflecting off the sample surface at an angle of $80^{\circ}$ and being detected with a liquid-nitrogen-cooled MCT detector. The sample compartment was continuously purged with dry air. The sample holder was suitably modified to be able to record spectra of different regions of the sample with a 2-mm aperture. Typically, 1,024 scans of multiplexed interferograms were collected with $4-\mathrm{cm}^{-1}$ resolution and processed with the OPUS software (Bruker Optics, Germany). The spectra were background corrected with a polynomial. 


\subsection{Atomic Force Microscopy (AFM)}

Atomic force microscopy (AFM, Dimension 3000, Veeco Metrology Group, Santa Barbara, CA, USA) was employed to characterize the surface morphological and nanotribological properties of the samples. The surface morphology was characterized by TappingMode ${ }^{\mathrm{TM}} \mathrm{AFM}$; the $R_{\mathrm{a}}$ values of the SAM films were obtained by directly imaging the samples, whereas the $R_{\mathrm{a}}$ values of the PDMS pin were obtained by imaging the polystyrene master. A tappingmode silicon cantilever and tip (PointProbe ${ }^{\circledR}$ Plus, $k=92 \mathrm{~N} / \mathrm{m}, f_{0}=330 \mathrm{kHz}$, Germany) was used as a probe. Nanotribological properties of the SAM films were characterized by contact-mode AFM under distilled water $(>18 \mathrm{M} \Omega$ ). Based on the conventional beam-deflection and four-quadrant photodetector method [1, 2, 29], the interfacial friction force between a sample and a tip was measured as a function of applied load. Under a fixed load, the friction force was obtained by subtracting the lateral force obtained during retrace from that obtained during trace in a 'friction loop' [29, 44]. The friction force under a given load was obtained at more than 10 different positions on the samples for statistical evaluation. The scan length was $1 \mu \mathrm{m}$ and the sliding speed $2 \mu \mathrm{m} / \mathrm{s}$. This procedure was repeated by varying the applied load. Since the purpose of the AFM nanotribological studies in this work is to provide a reference for the relative order of frictional forces of the SAM films on a nanoscopic contact scale, the normal spring constant value of the commercial silicon nitride cantilevers indicated by the manufacturer (Nanoprobes, Veeco Metrology Group, Santa Barbara, CA, USA), $k_{\mathrm{N}}$ $(0.12 \mathrm{~N} / \mathrm{m})$, was employed without further calibration. In order to ensure valid comparison of the frictional data, however, all measurements were performed with an identical tip/cantilever assembly. The applied load varied between $10 \mathrm{nN}$ and $80 \mathrm{nN}$. Friction forces were expressed in arbitrary units, as received from the photodiode detector without further conversion. Along with friction measurements, the adhesive properties of the SAM films were also characterized by acquiring force-versus-distance curves using the identical tip/cantilever assembly. Prior to the measurements, the tip/cantilever assembly was immersed in a commercial acidic cleaning solution (Cleaner, COBAS INTEGRA ( $\mathrm{HCl} 300 \mathrm{mM}$, detergent 1\%), Roche, Germany) for $5 \mathrm{~min}$, followed by immersion in distilled water for $10 \mathrm{~min}$, and finally oxygen-plasma cleaning for $30 \mathrm{~s}$.

\subsection{Pin-on-disk Tribometry}

The macroscopic-scale tribological properties of the SAM films were characterized by means of pin-on-disk tribometry (CSM Instruments SA, Peseux, Switzerland). In this approach, the load was controlled by dead weights and the friction forces were measured by a strain gauge. After forming a contact between the loaded pin and the disk, the latter was rotated at a controlled speed by a motor, thus generating sliding friction forces. PDMS with an end-radius of $3 \mathrm{~mm}$ was employed as a standard pin material, but for comparison, a stainless steel ball (DIN 5401-20 G20, Hydrel AG, Romanshorn, Switzerland) with a radius of $3 \mathrm{~mm}$ was also employed as pin. The stainless steel ball was rinsed with ethanol, blown dry with nitrogen, and oxygen-plasma cleaned for $30 \mathrm{~s}$. The raw data for the friction forces were recorded as a function of time (or the number of rotations) over a fixed track, using the software (InstrumX version $2.5 \mathrm{~A})$ provided by the manufacturer. All measurements were carried out in distilled water $(>18 \mathrm{M} \Omega$ ).

The standard protocol for the friction measurements involves the acquisition of $\mu$-versus-speed plots ( $\mu=$ friction force/load) and friction-versus-load plots. For $\mu$-versus-speed plots, the speed was varied from $0.25 \mathrm{~mm} / \mathrm{s}$ to $100 \mathrm{~mm} / \mathrm{s}$ under a fixed load $(1 \mathrm{~N})$, and for frictionversus-load plots, the load was varied from $0.5 \mathrm{~N}$ to $5 \mathrm{~N}$ under two fixed speeds $(1 \mathrm{~mm} / \mathrm{s}$ and $50 \mathrm{~mm} / \mathrm{s})$. The number of rotations was 20 for each measurement. The average friction force from the latter half of these (11-20th) was obtained to avoid "running-in" effects. For control experiments involving the examination of the sliding track by PM-IRRAS, the number of rotations was extended to 500 under $1 \mathrm{~N}$.

\section{Results and Discussion}

\subsection{Initial Characterization of the SAM Films}

Before the start of the tribological experiments, the SAM films formed on thermally evaporated gold substrates were characterized by ellipsometry, water-contact-angle measurements, AFM, and PM-IRRAS. Ellipsometry revealed monolayer thicknesses of $1.57 \pm 0.11 \mathrm{~nm}$ for the $\mathbf{C}_{\mathbf{1 1}} \mathbf{O H}$, $1.43 \pm 0.13 \mathrm{~nm}$ for the $\mathbf{C}_{\mathbf{1 1}} \mathbf{C H}_{\mathbf{3}}$, and $0.47 \pm 0.52 \mathrm{~nm}$ for the $\mathbf{C}_{5} \mathbf{C H}_{3}$ SAM films. The refractive index for the organic layers was assumed to be 1.45 . The water contact angle, $\theta_{\mathrm{w}}$, for the $\mathbf{C}_{\mathbf{1 1}} \mathbf{O H}$ SAM film, $20 \pm 5^{\circ}$, was substantially lower than those for the $\mathbf{C}_{\mathbf{1 1}} \mathbf{C H}_{\mathbf{3}}, 109 \pm 2^{\circ}$, and the $\mathbf{C}_{5} \mathbf{C H}_{3}, 106 \pm 2^{\circ}$, films as well as that of bare gold substrate, $70 \pm 5^{\circ}$, which indicates the exposure of $-\mathrm{OH}$ $\left(\mathbf{C}_{11} \mathbf{O H}\right)$ and $-\mathrm{CH}_{3}\left(\mathbf{C}_{11} \mathbf{C H}_{3}\right.$ and $\left.\mathbf{C}_{5} \mathbf{C H}_{3}\right)$ groups on the surfaces of the corresponding SAM films. The average values and the standard deviation of water contact angles were obtained from more than 10 different measurements on three different samples for each SAM film. The slightly lower water contact angle of $\mathbf{C}_{5} \mathbf{C H}_{3}, 106^{\circ}$, than that of $\mathbf{C}_{11} \mathbf{C H}_{3}, 109^{\circ}$, on average, is generally ascribed to more 
probable exposure of methylene groups $\left(-\mathrm{CH}_{2}-\right)$ arising from the less well-packed backbone structure of $\mathbf{C}_{5} \mathbf{C H}_{\mathbf{3}}$ than $\mathbf{C}_{\mathbf{1 1}} \mathbf{C H}_{3}$ SAM film $[45,46]$. The $\theta_{\mathrm{w}}$ values of the $o x-$ PDMS surfaces were $<3^{\circ}$.

AFM revealed homogenously distributed grainy features of the gold substrates (diameter: a few tens of nm scale), which are typical morphological characteristics of thermally evaporated polycrystalline gold surfaces on glass or silicon oxide. The morphologies of the SAM films on the gold substrates were indistinguishable from those of the substrates, which supports the formation of homogenous, monolayer films. The $R_{\mathrm{a}}$ values obtained from the gold substrates over $1 \mu \mathrm{m} \times 1 \mu \mathrm{m}, \quad 10 \mu \mathrm{m} \times 10 \mu \mathrm{m}$, and $50 \mu \mathrm{m} \times 50 \mu \mathrm{m}$, were $1.3,1.4$, and $1.6 \mathrm{~nm}$, respectively (the error bars are $\pm 0.60 \mathrm{~nm}$ ), and those for the three SAM films were virtually identical. In parallel, the topographic images of the master for the PDMS pins were also obtained. Compared with the SAM films on gold substrates, slightly rougher surfaces, including some random features a few tens of $\mathrm{nm}$ in height, were observed. The $R_{\mathrm{a}}$ values obtained over $1 \mu \mathrm{m} \times 1 \mu \mathrm{m}, 10 \mu \mathrm{m} \times 10 \mu \mathrm{m}$, and $50 \mu \mathrm{m} \times 50 \mu \mathrm{m}$, were $1.2,2.4$, and $3.4 \mathrm{~nm}$, respectively (the error bars are $\pm 1.10 \mathrm{~nm}$ ).

Analysis by PM-IRRAS revealed more detailed information on the chemical and structural features of the SAM films. The asymmetric and symmetric methyl $\mathrm{C}-\mathrm{H}$ stretches, $v_{\mathrm{a}}\left(\mathrm{CH}_{3}\right)$ at $2,962 \mathrm{~cm}^{-1}$ and $v_{\mathrm{s}}\left(\mathrm{CH}_{3}\right)$ at $2,877 \mathrm{~cm}^{-1}$, respectively, and the band at $2,936 \mathrm{~cm}^{-1}$ assigned to a Fermi resonance (FR) between the $\mathrm{CH}_{3}$ symmetric stretching mode and overtones of bending modes, appear only for $\mathbf{C}_{11} \mathbf{C H}_{3}$ and $\mathbf{C}_{5} \mathbf{C H}_{3}$ SAM films, but are absent for $\mathbf{C}_{\mathbf{1 1}} \mathbf{O H}$ SAM films, as expected. The position and peak width of the methylene asymmetric $\mathrm{C}-\mathrm{H}$ stretching modes are particularly sensitive to the conformational order of the alkyl chains $[15,16,45-48]$. As seen in Fig. 3, the $v_{\mathrm{a}}\left(\mathrm{CH}_{2}\right)$ peak of the $\mathbf{C}_{\mathbf{1 1}} \mathbf{C H}_{\mathbf{3}}$ film appears at $2,919 \mathrm{~cm}^{-1}$, indicating a highly ordered hydrocarbon backbone structure. The $v_{\mathrm{a}}\left(\mathrm{CH}_{2}\right)$ peak of the $\mathbf{C}_{\mathbf{1 1}} \mathbf{O H}$ film was observed at a slightly

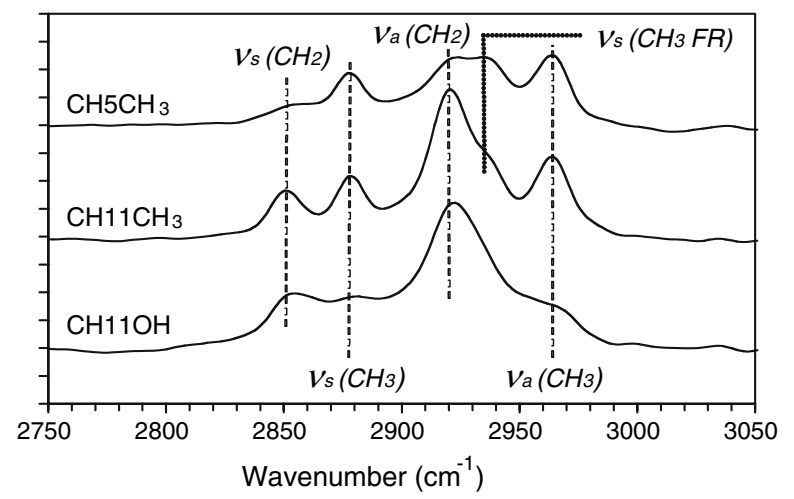

Fig. 3 PM-IRRA spectra obtained from the three alkanethiol SAM films higher value of $2,921 \mathrm{~cm}^{-1}$. In contrast, the $v_{\mathrm{a}}\left(\mathrm{CH}_{2}\right)$ peak of the $\mathbf{C}_{5} \mathbf{C H}_{3}$ film is poorly defined and appears much broader than those of the $\mathbf{C}_{\mathbf{1 1}} \mathbf{C H}_{\mathbf{3}}$ and $\mathbf{C}_{\mathbf{1 1}} \mathbf{O H}$ SAM films, which indicates that the conformation of the $\mathbf{C}_{\mathbf{5}} \mathbf{C H}_{\mathbf{3}}$ film is very disordered and liquid-like.

As a whole, these data verified that the three SAM films displaying (a) varying surface hydrophilicity $\left(\mathbf{C}_{\mathbf{1 1}} \mathbf{O H}\right.$ versus $\mathbf{C}_{\mathbf{1 1}} \mathbf{C H}_{\mathbf{3}} / \mathbf{C}_{\mathbf{5}} \mathbf{C H}_{\mathbf{3}}$ SAM films) and (b) varying conformational order of the alkyl chains $\left(\mathbf{C}_{\mathbf{1 1}} \mathbf{C H}_{\mathbf{3}}\right.$ versus $\mathbf{C}_{5} \mathbf{C H}_{3}$ SAM films) have been successfully generated on polycrystalline gold substrates.

\subsection{Nanotribological Properties of the SAM Films by Means of AFM}

The nanotribological properties of the SAM films generated from $\mathbf{C}_{\mathbf{1 1}} \mathbf{O H}, \mathbf{C}_{11} \mathbf{C H}_{3}$, and $\mathbf{C}_{5} \mathrm{CH}_{3} \mathrm{SAM}$ films were characterized through the measurement of frictional forces with a plasma-cleaned silicon nitride tip as a function of load under distilled water. Representative friction-versusload plots obtained by AFM are presented in Fig. 4a. The force-versus-distance curves obtained from the same three SAM films are shown in Fig. 4b. In order to ensure a statistically valid comparison, the measurements were repeated several times in varying order using the same tip/

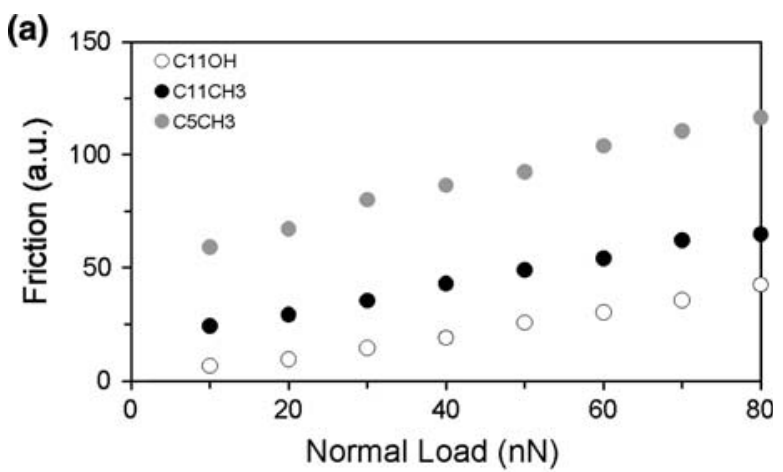

(b)

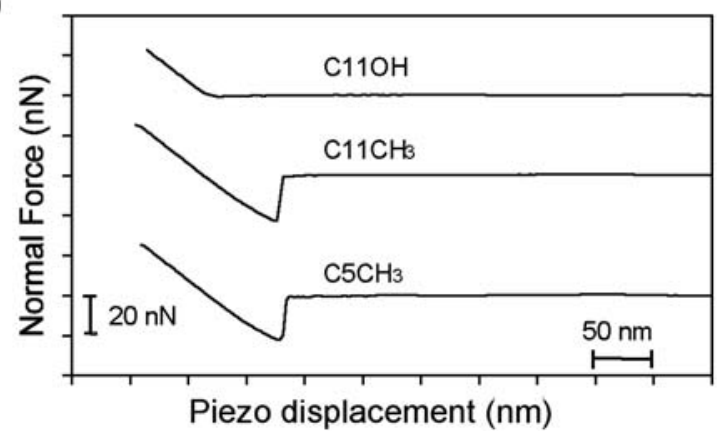

Fig. 4 (a) Friction force versus load plots and (b) force-versusdistance plots obtained from the interaction between an AFM tip and the three SAM films in distilled water 
cantilever assembly. Although minor differences were observed in the frictional and adhesive properties of the samples, the relative order of friction forces of the SAM films were consistently observed as in Fig. 4a: $\mathbf{C}_{5} \mathbf{C H}_{3}>$ $\mathbf{C}_{\mathbf{1 1}} \mathbf{C H}_{3}>\mathbf{C}_{\mathbf{1 1}} \mathrm{OH}$. This order is highly correlated with the order of 'pull-off forces' obtained from forceversus-distance curves as shown in Fig. $4 \mathrm{~b}: \mathbf{C}_{\mathbf{5}} \mathbf{C H}_{\mathbf{3}} \approx$ $\mathrm{C}_{11} \mathrm{CH}_{3}>\mathrm{C}_{11} \mathrm{OH}$.

As mentioned in Sect. 1, choice of the three SAMs in this work was motivated by an attempt to employ standard SAM systems whose tribological properties have been well established and, therefore, we can focus on the proposed test methodology. For the $\mathrm{CH}_{3}$-terminated normal alkanethiol or alkylsilane SAM films, it has been well known that longer hydrocarbon chains usually contribute to enhancing both the packing density and order of the backbone and, therefore, tend to lower the interfacial frictional properties [3-9]. While most previous nanotribological studies of these systems have been carried out under ambient conditions, we have now shown the same trend in distilled water: Alkyl-chain deformation still appears to be the dominant energy-dissipation mechanism for the two $\mathrm{CH}_{3}$-terminated SAM films.

$\mathrm{C}_{11} \mathrm{OH}$ and $\mathrm{C}_{11} \mathrm{CH}_{3}$ SAM films display similarly wellordered backbones, are constructed from identical hydrocarbon chains, and yet present different terminal groups $\left(\mathrm{OH}-\right.$ versus $\mathrm{CH}_{3}-$ ). The tribological properties of SAM films displaying chemically different terminal groups are known to be closely associated with their adhesive properties, which are, in turn, dependent on both the chemical identity of the counterface and the medium in which the tribological interaction takes place [9-18]. Since the oxygen-plasma-treated silicon nitride AFM probe in this work displays hydrophilic surface characteristics (OH-groups), the work of adhesion between two hydrophilic surfaces (the AFM probe versus $\mathbf{C}_{\mathbf{1 1}} \mathbf{O H}$ ) is apparently lower than that involving a hydrophobic surface (the AFM probe versus $\mathbf{C}_{\mathbf{1 1}} \mathbf{C H}_{3}$ ) in aqueous media [11], as shown in Fig. 4b. The difference in the adhesive forces for these two SAM films with the AFM probe is thus mainly responsible for the difference in the nanotribological properties.

Overall, the nanotribological properties of the SAM films revealed by AFM in this work serve as a reference for the intrinsic tribological properties of the films imparted by their structural and chemical features in a wear-less contact regime.

\subsection{Elastomeric Sliding Contact on the SAM Films on a Macroscopic Scale}

Our primary interest in employing an elastomeric (PDMS) pin as the sliding partner for these three SAM films is to test if the alkyl-chain-dependent $\left(\mathbf{C}_{5} \mathbf{C H}_{\mathbf{3}}\right.$ versus $\mathbf{C}_{\mathbf{1 1}} \mathbf{C H}_{\mathbf{3}}$
SAMs) and terminal-functional-group-dependent $\left(\mathbf{C}_{\mathbf{1 1}} \mathbf{C H}_{\mathbf{3}}\right.$ versus $\mathbf{C}_{\mathbf{1 1}} \mathbf{O H}$ SAMs) frictional properties, as observed in AFM experiment (Fig. 4), can be reproduced on a macroscopic scale. Figure 5a shows that this is indeed the case; When the friction-versus-load plots were obtained from the sliding contacts between $o x$-PDMS pins, which are chemically similar to the oxidized silicon nitride AFM tip, and the three SAM films in distilled water; the same order of the interfacial frictional properties, $\mathbf{C}_{5} \mathbf{C H}_{\mathbf{3}}>\mathbf{C}_{\mathbf{1 1}} \mathbf{C H}_{\mathbf{3}}>$ $\mathbf{C}_{\mathbf{1 1}} \mathbf{O H}$, was measured at $1 \mathrm{~mm} / \mathrm{s}$. This trend was consistently observed from the friction-versus-load plot obtained at much higher sliding speed, $50 \mathrm{~mm} / \mathrm{s}$, as shown in Fig. 5 b. However, the $\mu$ values at $50 \mathrm{~mm} / \mathrm{s}$ are significantly lower than those at $1 \mathrm{~mm} / \mathrm{s}$ for all three SAMs: for
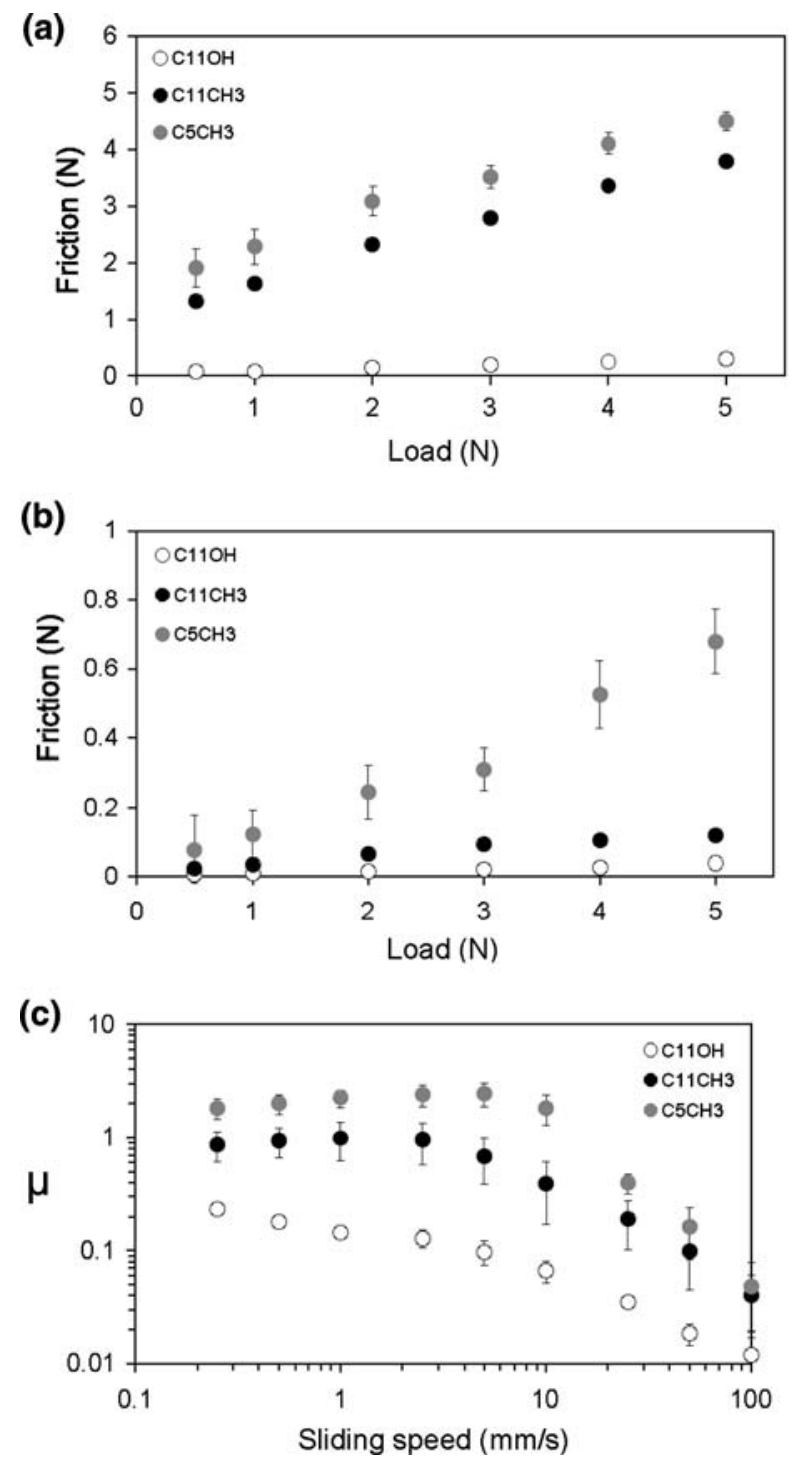

Fig. 5 (a) Friction-force-versus-load plots (sliding speed $=1 \mathrm{~mm} / \mathrm{s}$ ), (b) friction-force-versus-load plots (sliding speed $=50 \mathrm{~mm} / \mathrm{s}$ ) and (c) $\mu$-versus-speed plots (load $=1 \mathrm{~N}$ ) obtained from the tribopair of $o x$ PDMS/SAM films in distilled water 
instance, $0.008(50 \mathrm{~mm} / \mathrm{s})$ vs. $0.061(1 \mathrm{~mm} / \mathrm{s})$ for the C11OH film, 0.024 vs. 0.76 for the $\mathbf{C}_{\mathbf{1 1}} \mathbf{C H}_{\mathbf{3}}$ film, and 0.14 vs. 0.90 for the $\mathbf{C}_{5} \mathbf{C H}_{3}$ film, under the load of $5 \mathrm{~N}$. The speed-dependent frictional behavior of the sliding contacts of the $o x$-PDMS/SAM films is more clearly seen in the $\mu$-versus-speed plots $($ load $=1 \mathrm{~N})$, as shown in Fig. $5 \mathrm{c}$. While the $\mu$ values were generally decreasing with increasing speed for all cases, the onset of the decrease in $\mu$ appears to be dependent on the hydrophilicity of the SAM films. For the two $\mathrm{CH}_{3}$-terminated SAM films, for instance, the $\mu$ values started to decrease from ca. $5 \mathrm{~mm} / \mathrm{s}$, reaching 0.04-0.05 at the highest speed, whereas the decrease of $\mu$ for the $\mathbf{C}_{\mathbf{1 1}} \mathbf{O H}$ SAM started from the lowest speed, $0.25 \mathrm{~mm} / \mathrm{s}$, gradually to the highest speed, $100 \mathrm{~mm} / \mathrm{s}$, reaching a lowest value of $\mu \sim 0.01$. These observations suggest that the lubrication mechanisms in the low- and high-speed regimes might be different, despite the same relative order of the frictional properties of the three SAM films. This issue will be discussed in detail in Sect. 3.5.

When the SAM films were slid against a hydrophilic (oxygen-plasma treated), yet rigid slider, a stainless steel pin, wear of the film and the substrate became so significant that the structural and chemical characteristics of SAM films were not discernable any more, as shown in Fig. 6. Due to the apparent damage on the sliding track for each measurement, the sliding track was changed for each speed condition, and the $\mu$ values remained constant at ca. 0.15 over the entire range of speed for all three samples (two SAM films and bare gold substrate). Although some previous macrotribological studies using a rigid slider have revealed alkyl-chain-length-dependent frictional properties of SAMs, this distinction was possible only under a load of a few $\mathrm{mN}$ [20].

The pin-on-disk tribometer experiments in this work have thus revealed that the frictional properties of the SAM films observed by AFM could be reproduced on a macroscopic contact scale by employing a hydrophilic elastomeric slider.

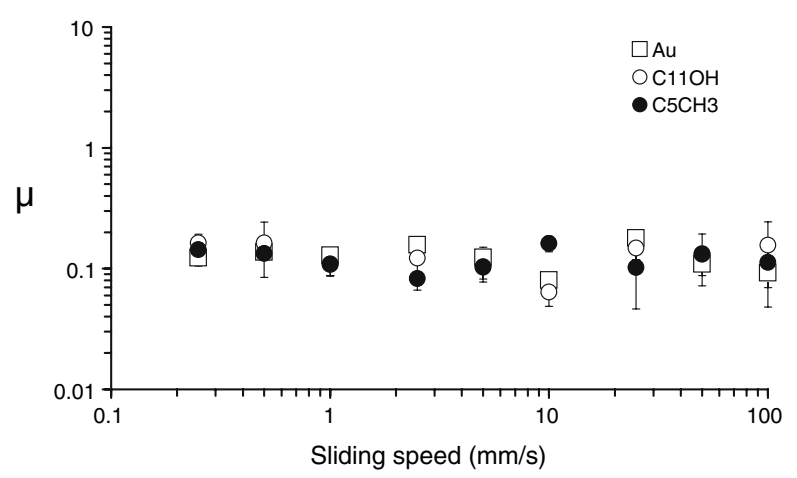

Fig. $6 \mu$-versus-speed plots (load = $1 \mathrm{~N})$ obtained from the tribopair of stainless steel/SAM films in distilled water

\subsection{PM-IRRAS Studies on the Sliding Track}

One distinct advantage of the macrotribological versus nanotribological approach is that the sliding tracks are generally wide enough to be accessed by standard surfacespectroscopic tools. Given that the tribological properties of the three SAM films characterized by pin-on-disk tribometer using an elastomer slider, $o x$-PDMS, revealed the same order of frictional properties as were observed by $\mathrm{AFM}$, it is of interest to examine if the SAM films retain their structural integrity following tribological stress. It is noted that most tribological experiments on SAM films by AFM are believed to take place in a wear-less regime. However, no direct spectroscopic evidence is currently available due to the very small contact area involved. In this work, we have employed PM-IRRAS to examine the molecular structure of the SAM films following tribological stress applied by the elastomeric slider. For these experiments, the sliding of $o x$-PDMS pin against the $\mathbf{C}_{\mathbf{1 1}} \mathbf{O H}$ and $\mathbf{C}_{11} \mathbf{C H}_{3}$ SAM films was extended to 500 rotations at $1 \mathrm{~mm} / \mathrm{s}$ and $1 \mathrm{~N}$. The PM-IRRA spectra obtained from inside and outside the sliding tracks are compared in Fig. 7. In Fig. 7a, the spectral region sensitive to the characteristic structural features of the SAM films is shown. Firstly, it is notable that the peak positions for the asymmetric methylene $\mathrm{C}-\mathrm{H}$ stretch, $v_{\mathrm{a}}\left(\mathrm{CH}_{2}, \quad 2,919\right.$ $2,921 \mathrm{~cm}^{-1}$ ), are virtually identical for inside (solid line) and outside (dotted line) the sliding track, which indicates that the SAM films remain intact and retain a nearly wellordered backbone structure despite the tribological stress. Secondly, the intensity of the asymmetric methyl $\mathrm{C}-\mathrm{H}$ stretch, $v_{\mathrm{s}}\left(\mathrm{CH}_{3}\right.$, ca. $\left.2,962 \mathrm{~cm}^{-1}\right)$ has somewhat increased inside the sliding track, and this change is more significant for the cases of $\mathbf{C}_{\mathbf{1 1}} \mathbf{C H}_{\mathbf{3}}$ SAM than of $\mathbf{C}_{\mathbf{1 1}} \mathbf{O H}$ SAM. The increase in the intensity of the asymmetric methyl $\mathrm{C}-\mathrm{H}$ stretch peak coincides with the occurrence of the peaks at 1,110 and $1,265 \mathrm{~cm}^{-1}$ (arising from $\mathrm{Si}-\mathrm{O}$ asymmetric stretching and $\mathrm{Si}-\mathrm{CH}_{3}$ asymmetric bending modes, respectively [48]) inside the sliding track, as shown in Fig. $7 \mathrm{~b}$, which suggests that the transfer of uncrosslinked monomer species from the pin to the SAM films might have occurred. In order to test this hypothesis, we have repeated the same experiments after extracting uncrosslinked monomer species from the PDMS pin network (see the Sect. 2.2 for extraction process). As shown in Fig. 7a, the PM-IRRA spectra corresponding to the $\mathrm{C}-\mathrm{H}$ stretching modes, from $2,750 \mathrm{~cm}^{-1}$ to $3,050 \mathrm{~cm}^{-1}$, obtained from inside and outside the sliding track are almost identical. A slight difference in peak intensity for some cases shown in Fig. 7 a was statistically not significant. The occurrence of $\mathrm{Si}-\mathrm{O}-\mathrm{Si}$ peaks in the low wavenumber region, Figure $7 \mathrm{~b}$, has also been substantially suppressed for all cases. However, the transfer of a trace amount of the monomer species 

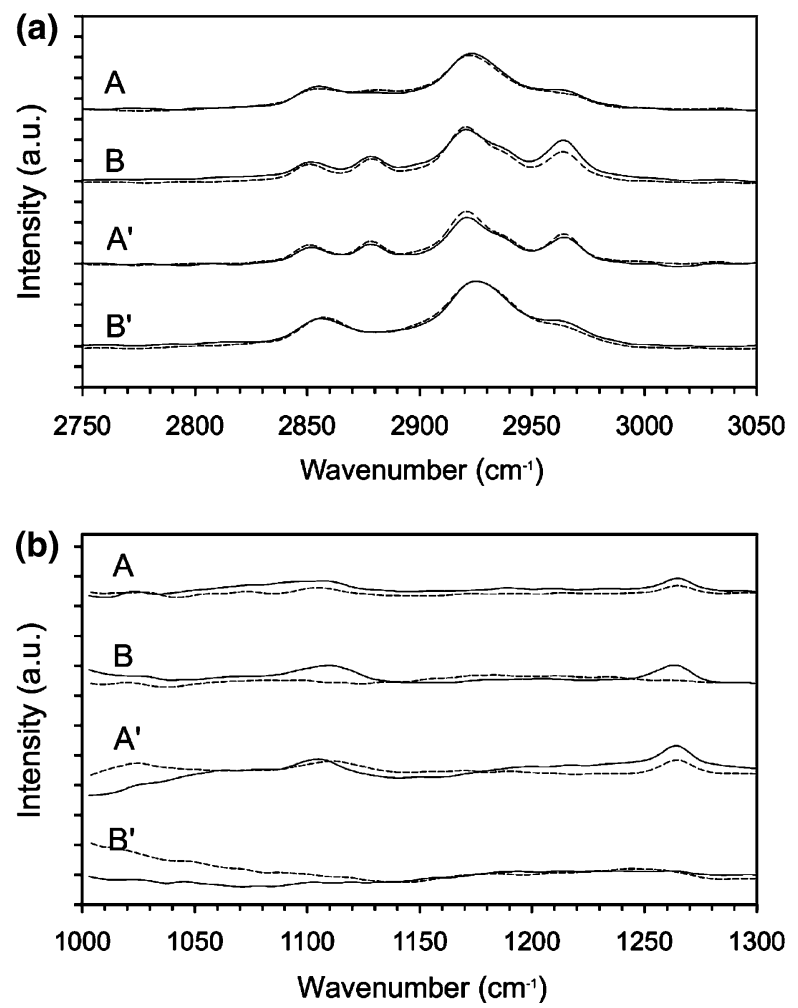

Fig. 7 PM-IRRA spectra obtained from inside and outside the sliding track of the SAM films. (a) the spectral region sensitive to the characteristic structural features of the SAM films, (b) the spectral region sensitive to the $\mathrm{Si}-\mathrm{O}-\mathrm{Si}$ stretching region (A: $o x$-PDMS/ $\mathbf{C}_{11} \mathbf{O H}, \mathrm{B}: o x$-PDMS/ $\mathbf{C}_{11} \mathbf{C H}_{3}, \mathrm{C}: o x$-PDMS (extracted)/ $\mathbf{C}_{\mathbf{1 1}} \mathbf{O H}, \mathrm{D}$ : $o x$-PDMS (extracted)/ $/ \mathbf{C}_{\mathbf{1 1}} \mathbf{C H}_{\mathbf{3}}$ ). The tribostress was applied by generating the sliding contacts between $o x$-PDMS/SAM films for 500 rotations $(\mathrm{load}=1 \mathrm{~N}$ and sliding speed $=1 \mathrm{~mm} / \mathrm{s})$

to $\mathbf{C}_{\mathbf{1 1}} \mathbf{O H}$ SAM film by ox-PDMS pins was observed to be not completely avoidable. The extraction of the monomer species from the PDMS pins, however, did not influence on the relative frictional properties of the SAM films shown in Fig. 5.

Spectroscopic examination of the sliding track by PMIRRAS clearly verified that the SAM films retain their ordered structure following the tribostress provided by the elastomeric slider. Analysis of the sliding track that has received the tribological stress is common practice in macrotribological studies of SAM films [20, 21, 24]; however, it was even easier when an elastomer was employed as the sliding partner because of the larger contact area achieved at the elastomeric interface. It should be emphasized that the spatially resolved PM-IRRAS measurements presented here were simply measured by positioning different regions of the sample in the beam path under normal sampling conditions and, therefore, the spectra presented above as "inside" the wear track do not completely exclude the beam sampling some of the area outside the track, as well. As a rough estimate, the fraction of the wear track probed by the beam in our measurement, assuming an ideally aligned beam path and sample positioning, is about $80 \%$. However, the reasonable resolution between inside and outside the sliding track by PM-IRRAS obtained even with such a simple set-up suggests that this approach holds potential as powerful research methodology. Although PM-IRRAS was employed mainly to verify the mechanical durability of the SAM films in this work, more diverse and systematic spectroscopic studies associated with tribological contacts are expected; the detection of the monomer transfer following the sliding contact between $o x$-PDMS/SAM films can be one example.

\subsection{Lubrication Mechanisms: The Transition from Boundary Lubrication to Soft EHL}

Another important aspect of macrotribometric approaches is that they can easily explore the high-speed regime. This feature is particularly advantageous when the tribological testing is carried out in a liquid medium as in this work; with increasing sliding speed, the entrainment of the liquid into the contact zone and the formation of the fluid film starts to occur, and thus the transition from boundary lubrication to fluid-film lubrication is also observed with increasing speed. Despite its extremely low pressurecoefficient of viscosity, water can also form a fluid-film lubricant layer when one or both sides of the tribopair is comprised of an elastomer, i.e., in the soft-EHL regime (also known as isoviscous-elastic lubrication regime) [3443]. The likelihood of the soft-EHL mechanism occurring and the corresponding fluid-film thickness for a given elastomeric tribosystem can be readily predicted according to the theoretical model described by Hamrock and Dowson [42] (later revised by Esfahanian and Hamrock [43]) based upon the bulk mechanical properties of the tribopair and the rheological properties of the lubricant. When expressed in terms of the material and measurement parameters, the minimum film thickness is

$h_{\min } \approx 2.1 \cdot R^{0.77} \cdot\left(\eta \cdot u_{\mathrm{s}}\right)^{0.66} \cdot E^{\prime-0.45} \cdot w^{-0.21}$

where $R$ is the radius of the slider for a sphere-on-plane contact $(3 \mathrm{~mm}), \eta$ is the viscosity of the lubricant $\left(9 \times 10^{-}\right.$

$\left.{ }^{4} \mathrm{~Pa} \mathrm{~s}\right), u_{\mathrm{s}}$ is the sliding speed (variable), $E^{\prime}$ is the reduced contact modulus, $E^{\prime}=2\left(\left(1-v_{1}^{2}\right) / E_{1}\right)+\left(\left(1-v_{2}^{2}\right) / E_{2}\right)$ where $v$ is Poisson ratio $\left(E_{\mathrm{PDMS}}=2 \mathrm{MPa}, E_{\text {glass }}=270\right.$ $\left.\mathrm{GPa}, v_{\mathrm{PDMS}}=0.5, v_{\text {glass }}=0.2\right)$ and $w$ is the applied load (variable). We have carried out the calculation of the film thickness by employing the parameters employed for the tribometer experiments (Figs. 4, 5). The results are shown in Fig. 8a and b. Since the film thickness predicted from Eq. 1 is that for ideally smooth surfaces $\left(R_{\mathrm{a}}=0\right)$, the 

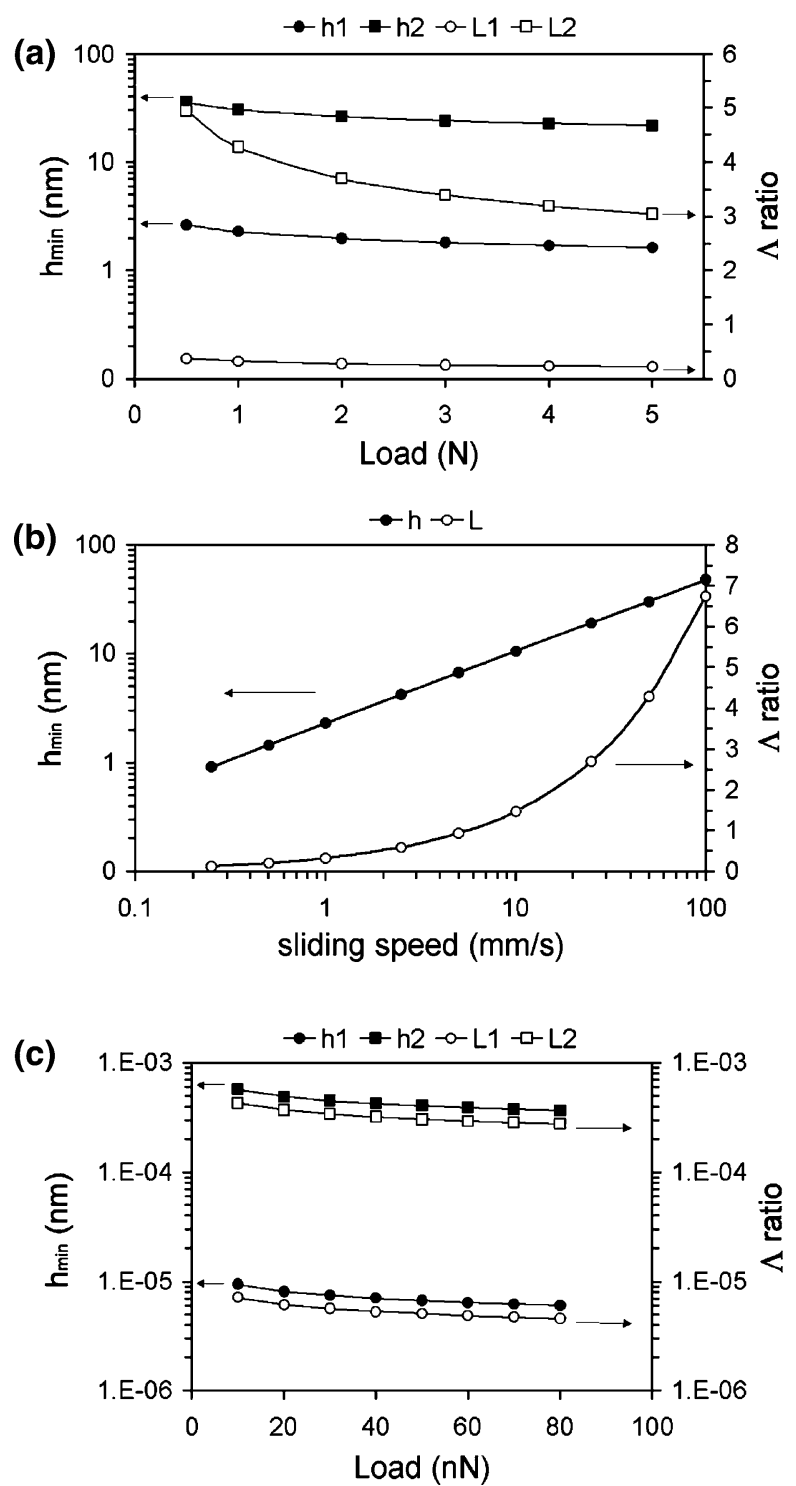

Fig. 8 The expected minimum film thickness calculated according to Eq. 1 for the sliding contacts between the tribopairs in distilled water and the $\Lambda$ ratio between the expected film thickness and the surface roughness $\left(\Lambda=h_{\min } / \sigma\right.$, where $h_{\min }$ is the minimum film thickness and $\sigma$ is the combined surface roughness of the tribopair, $\sigma=\sqrt{R_{\mathrm{a}}^{\text {pin }}+R_{\mathrm{a}}^{\text {disk }}}$ ) (a) for the tribopair of $o x$-PDMS/glass pair as a function of load $\left(\mathrm{h}_{1}\right.$ and $\mathrm{L}_{1}$ : sliding speed, $1 \mathrm{~mm} / \mathrm{s}$ and $\mathrm{h}_{2}$ and $\mathrm{L}_{2}$ : sliding speed, $50 \mathrm{~mm} / \mathrm{s}$ ) in water, (b) for the tribopair of $o x$-PDMS and glass as a function of speed in water (h: minimum film thickness, $\mathrm{L}: \Lambda$ ratio) and (c) for the tribopair of silicon nitride AFM probe and SAM film as a function of load in water $\left(\mathrm{h}_{1}\right.$ and $\mathrm{L}_{1}$ : sliding speed, $2 \mu \mathrm{m} / \mathrm{s}$ and $\mathrm{h}_{2}$ and $\mathrm{L}_{2}$ : sliding speed, $1,000 \mu \mathrm{m} / \mathrm{s}$ )

relative magnitude of the film thickness compared to the surface roughness can be taken into account by estimating the ratio between them, i.e., $\Lambda$ ratio $\left(\Lambda=h_{\min } / \sigma\right.$, where $\sigma$ is the combined surface roughness of the tribopair, $\sigma=\sqrt{R_{\mathrm{a}}^{\text {pin }}+R_{\mathrm{a}}^{\text {disk }}}$, and $h_{\text {min }}$ is the minimum film thickness). This $\Lambda$ ratio is often employed to estimate the lubrication mechanism for rough surfaces; generally, fluidfilm lubrication is expected when $\Lambda \geq 3$, and boundary lubrication is expected when $\Lambda \leq 1$, and mixed lubrication is expected when $1 \leq \Lambda \leq 3$ [49]. It is noted that due to the larger area of contact for the tribometer experiments in this work (mm-range in contact radius), the $R_{\mathrm{a}}$ values of the sample surfaces characterized by AFM (Sect. 3.1) are extrapolated to the corresponding scale.

Figure 8a shows that the $\Lambda$ ratio for the friction-versusload plots at $1 \mathrm{~mm} / \mathrm{s}$ ranged from $0.37(0.5 \mathrm{~N})$ to 0.23 $(5 \mathrm{~N})$, whereas those at $50 \mathrm{~mm} / \mathrm{s}$ ranged from 4.95 $(0.5 \mathrm{~N})$ to $3.05(5 \mathrm{~N})$, which suggests that the sliding contacts of $o x$-PDMS/SAM films might have occurred in different lubrication regimes in distilled water, i.e., boundary lubrication for $1 \mathrm{~mm} / \mathrm{s}$ and fluid-film lubrication for $50 \mathrm{~mm} / \mathrm{s}$. Although the experimental data for the fluid-film thickness are currently not available, significantly lower $\mu$ values observed from the friction-versusload plots at $50 \mathrm{~mm} / \mathrm{s}$ (Fig. $5 \mathrm{~b}$ ) compared with those at $1 \mathrm{~mm} / \mathrm{s}$ (Fig. 5a) are consistent with this argument. The $\Lambda$-ratio-versus-speed plots in Fig. $8 \mathrm{~b}$ shows that the transition to fluid-film lubrication, i.e., $\Lambda \geq 3$, is expected to occur from ca. $30 \mathrm{~mm} / \mathrm{s}$ in the case of an applied load of $1 \mathrm{~N}$.

It is emphasized that for the experiments carried out in distilled water, the occurrence of different lubrication mechanisms at different speeds was only to be expected for elastomeric contact on the macroscopic scale, such as the $o x$-PDMS/SAM film tribopairs tested by means of pin-on-disk tribometry. When the same calculation was carried out under the same experimental conditions for the AFM probe/SAM films tribopair $\left(E_{\mathrm{AFM}}\right.$ tip $=140 \mathrm{GPa}$, $E_{\mathrm{SAM}}=9.3 \mathrm{GPa}, \quad v_{\mathrm{AFM}}$ tip $=0.25, \quad v_{\mathrm{SAM}}=0.35, \quad R=$ $50 \mathrm{~nm}$, all the parameters quoted from the references [50] and [51]), the expected film thickness is in the range of ca. $10^{-5} \mathrm{~nm}$, and the $\Lambda$ ratio is smaller than $7.14 \times 10^{-6}$ as shown in Fig. 8c. Even if $1,000 \mu \mathrm{m} / \mathrm{s}$, upper speed limit of an ordinary AFM, is employed for the calculation of the film thickness, the expected film thickness is not higher than $5.71 \times 10^{-4} \mathrm{~nm}$ and the $\Lambda$ ratio is also not higher than $4.23 \times 10^{-4}$ as also shown in Figure 8(c). In other words, the transition from boundary lubrication to fluid-film lubrication is unlikely to occur for typical tribological contacts on SAM films by AFM probes in distilled water.

\subsection{Lubrication Mechanisms: the Role of Surface Chemistry}

The three SAM films employed in this work contributed to the modification of the interfacial frictional properties of the sliding contacts of elastomer/rigid substrate in two 
ways. Firstly, in the context of activating the fluid-film lubrication mechanism, the SAM films provided different surface hydrophilicities of the sliding track to vary the interfacial hydrophilicity of the tribopair; as addressed in a previous study involving self-mated PDMS sliding contacts in water [34], the bulk mechanical properties of the tribopairs and the surface roughness, discussed in the previous section, are, in practice, not the sole parameters that determine the activation of the soft-EHL mechanism: The surface chemistry of the tribopairs also plays a very significant role. Although the $\mathbf{C}_{\mathbf{1 1}} \mathbf{O H} \mathrm{SAM}$ is the most hydrophilic of the three SAM films used in this work with $\theta_{\mathrm{w}} \approx 25^{\circ}$, it is less hydrophilic than $o x$-PDMS, $\theta_{\mathrm{w}}<3^{\circ}$, and thus the $\mu$ values for $o x$-PDMS/ $\mathbf{C}_{11} \mathbf{O H}$ were observed to be generally higher than those of $o x$-PDMS/ $o x$-PDMS [34]. Secondly, in the boundary-lubrication regime, where the formation of the soft-EHL film is not expected (i.e., $\Lambda<1$ ), both surface chemistry and the structural integrity of the SAM films influenced the interfacial frictional properties in a similar fashion to that observed in AFM experiments. In terms of surface chemistry, the hydrophilic $\mathbf{C}_{\mathbf{1 1}} \mathbf{O H}$ SAM showed lower frictional forces than those observed for the two $\mathrm{CH}_{3^{-}}$ terminated SAMs when sliding against an $o x$-PDMS pin in the low-speed and/or high-load regime; under such conditions, however, this trend was not due to the higher feasibility of forming aqueous fluid-film, but rather due to the lower work of adhesion for the hydrophilic interface in an aqueous environment, similarly to the AFM experiments shown in the Sect. 3.2. In terms of the structural integrity, the $\mathbf{C}_{\mathbf{1 1}} \mathbf{C H}_{\mathbf{3}}$ SAM revealed lower frictional forces than the $\mathbf{C}_{5} \mathbf{C H}_{3}$ SAM for all cases, again mirroring the AFM experiments.

\section{Conclusions}

In this work, we have demonstrated that the intrinsic frictional properties of three alkanethiol SAM films, previously assessed by nanotribological approaches only, can be manifested on a macroscopic scale by employing an elastomer, PDMS, as the sliding partner in pin-on-disk tribometery. This approach provides unique opportunities to investigate the tribological properties of SAM films that have hitherto not been accessible by either conventional macrotribological or nanotribological approaches. Firstly, while the contact pressure can be maintained low enough to retain the integrity of SAM films, as with nanotribological approaches, high-speed, macroscale tribological contacts can be achieved by employing a pin-on-disk tribometer with an elastomeric counterface. Secondly, the wide sliding tracks generated in this approach-even wider than those obtained in conventional tribometry using rigid sliders-allow for standard spectroscopic approaches to access the contact area and characterize the influence of the tribological contacts on the SAM films. Thirdly, by running the measurements in a liquid medium, it is possible to induce a range of lubrication regimes, from boundary lubrication to fluid-film lubrication, over the speed range available from an ordinary pin-on-disk tribometer. Given that a large toolbox of self-assembly approaches to controlling surface chemistry has been established, this approach possesses the potential for systematic studies to investigate the influence of surface chemistry on elastomerbased tribological systems.

\section{References}

1. Carpick, R.W., Salmeron, M.: Scratching the surface: fundamental investigations of tribology with atomic force microscopy. Chem. Rev. 97(4), 1163-1194 (1997)

2. Leggett, G.J., Brewerb, N.J., Chonga, K.S.L.: Friction force microscopy: towards quantitative analysis of molecular organisation with nanometre spatial resolution. Phys. Chem. Chem. Phys. 7, 1107-1120 (2007)

3. Xiao, X., Hu, J., Charych, D.H., Salmeron, M.: Chain length dependence of the frictional properties of alkylsilane molecules self-assembled on mica studied by atomic force microscopy. Langmuir 12, 235-237 (1996)

4. Lio, A., Charych, D.H., Salmeron, M.: Comparative atomic force microscopy study of the chain length dependence of frictional properties of alkanethiols on gold and alkylsilanes on mica. J. Phys. Chem. B 101, 3800-3805 (1997)

5. Wong, S.-S., Takano, H., Porter, M.D.: Mapping orientation differences of terminal functional groups by friction force microscopy. Anal. Chem. 70, 5209-5212 (1998)

6. Lee, S., Shon, Y.-S., Colorado, R. Jr., Guenard, R.L., Lee, T.R., Perry, S.S.: The influence of packing densities and surface order on the frictional properties of alkanethiol self-assembled monolayers (SAMs) on gold: a comparison of SAMs derived from normal and spiroalkanedithiols. Langmuir 16, 2220-2224 (2000)

7. van der Vegte, E.W., Subbotin, A., Hadziioannou, G.: Nanotribological properties of unsymmetrical $n$-dialkyl sulfide monolayers on gold: effect of chain length on adhesion, friction, and imaging. Langmuir 16, 3249-3256 (2000)

8. Beake, B.D., Leggett, G.J.: Variation of frictional forces in air with the composition of heterogeneous organic surfaces. Langmuir 16, 735-739 (2000)

9. Brewer, N.J., Beake, B.D., Leggett, G.J.: Friction force microscopy of self-assembled monolayers: influence of adsorbate alkayl chain length, terminal group chemistry, and scan velocity. Langmuir 17, 1970-1974 (2001)

10. Frisbie, C.D., Rozsnyai, L.F., Noy, A., Wrighton, M.S., Lieber, C.M.: Functional group imaging by chemical force microscopy. Science 265, 2071-2074 (1994)

11. Sinniah, S.K., Steel, A.B., Miller, C.J., Reutt-Robey, J.E.: Solvent exclusion and chemical contrasts in scanning force microscopy. J. Am. Chem. Soc. 118, 8925-8931 (1996)

12. Vezenov, D.V., Noy, A., Rozsnyai, L.F., Lieber, C.M.: Force titration and ionization state sensitive imaging of functional groups in aqueous solution by chemical force microscopy. J. Am. Chem. Soc. 119, 2006-2015 (1997)

13. Noy, A., Vezenov, D.V., Lieber, C.M.: Chemical force microscopy. Annu. Rev. Mater. Sci. 27, 381-421 (1997) 
14. Kim, H.I., Koini, T., Lee, T.R., Perry, S.S.: Systematic studies of the frictional properties of fluorinated monolayers with atomic force microscopy: comparison of $\mathrm{CF}_{3}-$ and $\mathrm{CH}_{3}$-terminated films. Langmuir 13, 7192-7196 (1997)

15. Kim H.I., Graupe, M., Oloba, O., Koini, T., Imaduddin, S., Lee, T.R., Perry, S.S.: Molecularly specific studies of the frictional properties of monolayer films: a systematic comparison of $\mathrm{CF}_{3}-$, $\left(\mathrm{CH}_{3}\right)_{2} \mathrm{CH}$-, and $\mathrm{CH}_{3}$-terminated films. Langmuir 15, 3179-3185 (1999)

16. Lee, S., Puck, A., Graupe, M., Colorado, R. Jr., Shon, Y.-S., Lee, T.R., Perry, S.S.: Structure, wettability, and frictional properties of phenyl-terminated self-assembled monolayers on gold. Langmuir 17, 7364-7370 (2001)

17. Clear, S.C., Nealey, P.F.: Chemical force microscopy study of adhesion and friction between surfaces functionalized with selfassembled monolayers and immersed in solvents. J. Colloid Interface Sci. 213, 238-250 (1999)

18. Clear, S.C., Nealey, P.F.: Lateral force microscopy study of the frictional behavior of self-assembled monolayers of octadecyltrichlorosilane on silicon/silicon dioxide immersed in $n$-alcohols. Langmuir 17, 720-732 (2001)

19. Ren, S., Yang, S., Zhao, Y., Zhou, J., Xu, T., Liu, W.: Friction and wear studies of octadecyltrichlorosilane SAM on silicon. Tribol. Lett. 13, 233-239 (2002)

20. Nakano, M., Ishida, T., Numata, T., Ando, Y., Sasaki, S.: Alkyl chain length effect on tribological behavior of alkanethiol selfassembled monolayers on Au. Jpn. J. Appl. Phys. 42, 4734-4738 (2003)

21. Nakano, M., Ishida, T., Numata, T., Ando, Y., Sasaki, S.: Tribological behavior of terphenyl self-assembled monolayer studied by a pin-on-plate method and friction force microscopy. Jpn. J. Appl. Phys. 43, 4619-4623 (2004)

22. Sung, I.H., Kim, D.-E.: Surface damage characteristics of selfassembled monolayers of alkanethiols on metal surfaces. Tribol. Lett. 17, 835-844 (2004)

23. Ishida, H., Koga, T., Morita, M., Otsuka, H., Takahara, A.: Macro- and nanotribological properties of organosilane monolayers prepared by a chemical vapor adsorption method on silicon substrates. Tribol. Lett. 19, 3-8 (2005)

24. Nicholas, A. Jr., Street, S.C.: Spectroscopic analysis of the tribological behavior of a model boundary layer lubricant. Analyst 126, 1269-1273 (2001)

25. Hardy, W.B., Bircumshaw, I.: Boundary lubrication-plane surfaces and the limitations of Amonton's law. Proc. R. Soc. (Lond.) A 108, 1-27 (1925)

26. Tabor, D.: Mechanism of boundary lubrication. Proc. R. Soc. Ser. A 212, 498-505 (1952)

27. Levine, O., Zisman, W.A.: Physical properties of monolayers adsorbed at the solid-air interface. I. Friction and wettability of aliphatic polar compounds and effect of halogenation. J. Phys. Chem. 61, 1068-1077 (1957)

28. Levine, O., Zisman, W.A.: Physical properties of monolayers adsorbed at the solid-air interface. II. Mechanical durability of aliphatic polar compounds and effect of halogenation. J. Phys. Chem. 61, 1188-1196 (1957)

29. Mate, C.M., McClelland, G.M., Erlandsson, R., Chiang, S.: Atomic-scale friction of a tungsten tip on a graphite surface. Phys. Rev. Lett. 59, 1942-1945 (1987)

30. Carpick, R.W., Agrait, N., Ogletree, D.F., Salmeron, M.: Measurement of interfacial shear (friction) with an ultrahigh vacuum atomic force microscope. J. Vac. Sci. Technol. B 14, 1289-1295 (1996)

31. Brown, H.R.: Chain pullout and mobility effects in friction and lubrication. Science 263, 1411-1413 (1994)
32. Greenwood, J.A., Minshall, H., Tabor, D.: Hysterersis losses in rolling and sliding friction. Proc. R. Soc. Ser. A 259, 480-507 (1961)

33. Schallamach, A.: How does rubber slide? Wear 17, 301-312 (1971)

34. Lee, S., Spencer, N.D.: Aqueous lubrication of polymers: influence of surface chemical modification. Tribol. Int. 38, 922-930 (2005)

35. Lee, S., Iten, R., Müller, M., Spencer, N.D.: Influence of molecular architecture on the adsorption of poly(ethylene oxide)poly(propylene oxide)-poly(ethylene oxide) (PEO-PPO-PEO) on PDMS surfaces and implications for aqueous lubrication. Macromolecules 37, 8349-8356 (2004)

36. de Vincente, J., Strokes, J.R., Spikes, H.A.: Lubrication properties of non-absorbing polymer solutions in softelastohydrodynamic (EHD) contacts. Tribol. Int. 38, 515-526 (2005)

37. Roberts, A.D., Tabor, D.: The extrusion of liquids between highly elastic solids. Proc. R. Soc. Lond. A 325, 323-345 (1971)

38. Moore, D.F.: The elastohydrodynamic transition speed for spheres sliding on lubricated rubber. Wear 35, 159-170 (1975)

39. Medley, J.B., Strong A.B., Pilliar, R.M., Wong, E.W.: The breakdown of fluid film lubrication in elastic-isoviscous point contacts. Wear 63, 25-40 (1980)

40. Richards, S.C., Roberts, A.D.: Boundary lubrication of rubber by aqueous surfactant. J. Phys. D 25, A76-A80 (1992)

41. Dowson, D., Jin, Z.M.: Microelastohydrodynamic lubrication of low-elastic-modulus solids on rigid substrates. J. Phys. D 25, A116-A123 (1992)

42. Hamrock, B.J., Dowson, D.: Minimum film thickness in elliptical contacts for different regimes of fluid-film lubrication. Proceedings of the 5th Leeds-Lyon Symposium on Tribology, pp. 22-27. Mech. Eng. Publ. Bury St. Edmunds, Suffolk (1979)

43. Esfahanian, M., Hamrock, B.J.: Fluid-film lubrication regimes revisited. Tribol. Trans. 34, 628-632 (1991)

44. Marti, A., Hähner, G., Spencer, N.D.: Sensitivity of frictional forces to $\mathrm{pH}$ on a nanometer scale: a lateral force microscopy study. Langmuir 11, 4632-4635 (1995)

45. Nuzzo, R.G., Dubois, L.H., Allara, D.L.: Fundamental studies of microscopic wetting on organic surfaces. 1. Formation and structural characterization of a self-consistent series of polyfunctional organic monolayers. J. Am. Chem. Soc. 112, 558-569 (1990)

46. Nuzzo, R.G., Fusco, F.A., Allara, D.L.: Spontaneously organized molecular assemblies. 3. Preparation and properties of solution adsorbed monolayers of organic disulfides on gold surfaces. J. Am. Chem. Soc. 109, 2358-2368 (1987)

47. Bensebaa, F., Voicu, R., Huron, L., Ellis, T.H.: Kinetics of formation of long-chain $n$-alkanethiolate monolayers on polycrystalline gold. Langmuir 13, 5335-5340 (1997)

48. Truong, K.D., Rowntree, P.A.: Formation of self-assembled butanethiol monolayers of $\mathrm{Au}$ substrate: spectroscopic evidence for highly ordered island formation in sub-monolayer films. J. Phys. Chem. 100, 19917-19926 (1996)

49. Hutchings, I.M.: Ch.4 lubricants and lubrication In: Tribology; Friction and Wear of Engineering Materials. Edward Arnold (1992)

50. Barrena, E., Kopta, S., Ogletree, D.F., Charych, D.H., Salmeron, M.: Relationship between friction and molecular structure: alkylsilane lubricant films under pressure. Phys. Rev. Lett. 82, 28802883 (1999)

51. Weihs, T.P., Nawaz, Z., Jarvis, S.P., Pethica, J.B.: Limits of imaging resolution for atomic force microscopy of molecules. Appl. Phys. Lett. 59, 3536-3538 (1991) 